\title{
Polymorphism of 41 kD Flagellin Gene and Its Human B-Cell Epitope in Borrelia burgdorferi Strains of China
}

\author{
Huixin Liu, ${ }^{1,2}$ Wei Liu, ${ }^{1,2}$ Xuexia Hou, ${ }^{1,2}$ Lin Zhang, ${ }^{1,2}$ Qin Hao, ${ }^{1,2}$ and Kanglin Wan ${ }^{1,2}$ \\ ${ }^{1}$ State Key Laboratory for Infectious Disease Prevention and Control, National Institute for \\ Communicable Disease Control and Prevention, Chinese Center for Disease Control and Prevention, Beijing 102206, China \\ ${ }^{2}$ Collaborative Innovation Center for Diagnosis and Treatment of Infectious Diseases, Hangzhou 310003, China
}

Correspondence should be addressed to Qin Hao; haoqin75@hotmail.com and Kanglin Wan; wankanglin@icdc.cn

Received 14 June 2016; Accepted 4 October 2016

Academic Editor: Marcelo A. Soares

Copyright (c) 2016 Huixin Liu et al. This is an open access article distributed under the Creative Commons Attribution License, which permits unrestricted use, distribution, and reproduction in any medium, provided the original work is properly cited.

\begin{abstract}
The $41 \mathrm{kD}$ flagellin of Borrelia burgdorferi (B. burgdorferi) is a major component of periplasmic flagellar filament core and a good candidate for serodiagnosis in early stage of Lyme disease. Here, we chose 89 B. burgdorferi strains in China, amplified the gene encoding the $41 \mathrm{kD}$ flagellin, and compared the sequences. The results showed that genetic diversity presented in the $41 \mathrm{kD}$ flagellin genes of all 89 strains among the four genotypes of B. burgdorferi, especially in the genotype of B. garinii. Some specific mutation sites for each genotype of the $41 \mathrm{kD}$ flagellin genes were found, which could be used for genotyping B. burgdorferi strains in China. Human B-cell epitope analysis showed that thirteen of 15 nonsynonymous mutations occurred in the epitope region of $41 \mathrm{kD}$ flagellin and thirty of $42 \mathrm{~B}$-cell epitopes were altered due to all 13 nonsynonymous mutations in the epitope region, which may affect the function of the antigen. Nonsynonymous mutations and changed human B-cell epitopes exist in $41 \mathrm{kD}$ flagellin of $B$. burgdorferi sensu lato strains; these changes should be considered in serodiagnosis of Lyme disease.
\end{abstract}

\section{Introduction}

Lyme disease is a widespread, systemic disease caused by $B$. burgdorferi, which is transmitted to human by Ixodes ticks [1, 2]. Its incidence varies between countries, with approximately 65,500 patients annually in Europe [3,4]. Approximately 30,000 new cases of LD occur in the United States each year $[5,6]$. Many studies have confirmed that B. burgdorferi is phenotypically and genotypically heterogeneous. To date, 18 B. burgdorferi genospecies have been described; at least four of these species, B. burgdorferi sensu stricto (B.b.s.s), B. garinii, B. afzelii, and B. spielmanii, are associated with human infection [7-10]. The common causative LD agent in North America is Borrelia burgdorferi sensu stricto (B.b.s.s). In Europe and Asia, Borrelia garinii and Borrelia afzelii are the most abundant species [11, 12]. Clinical manifestations of Lyme disease are diverse, mainly including erythema migrans (EM) skin lesions, acrodermatitis chronica atrophicans, and neurotropic and arthritogenic symptoms. Laboratory evidence of infection, mainly serology, is essential for diagnosis, except in the case of typical EM. Immunological and molecular biological characterization of B. burgdorferi has led to the identification of several antigens that may be useful in the development of improved diagnostic methods and vaccines [13].

The $41 \mathrm{kD}$ flagellin is encoded by the gene $f l a B$ and is a major component of $B$. burgdorferi's periplasmic flagellar filament core. Recently, a study by Sultan et al. [14] demonstrated that flaB mutant of $B$. burgdorferi was nonmotile. They also found that whereas wild-type cells were motile and had a flat-wave morphology, flaB mutant cells were nonmotile and rod shaped. Hence, the $41 \mathrm{kD}$ flagellin is critical for optimal survival in ticks and infection of the mammalian host by the arthropod tick vector. Moreover, the first detectable specific immunoglobulin (Ig) M and IgG responses were directed to the $41 \mathrm{kD}$ flagellin in the patients with B. burgdorferi infection [15]. It makes this antigen important for serodiagnosis. The $41 \mathrm{kD}$ flagellin is the most human B-cell epitope-harbored antigen containing forty-four B-cell epitopes [16], which suggest that it may play an important role in the immune 
TABLE 1: Distribution of strains in different areas of China.

\begin{tabular}{lc}
\hline Areas & Number of isolates \\
\hline Jilin Province & 31 \\
Guangdong Province & 2 \\
Inner Mongolia (Neimeng) & 11 \\
Shandong Province & 1 \\
Liaoning Province & 2 \\
Guizhou Province & 7 \\
Sichuan Province & 6 \\
Heilongjiang Province & 9 \\
Xinjiang Uygur Autonomous Region & 15 \\
Beijing Municipality & 3 \\
Hebei Province & 1 \\
Hunan Province & 1 \\
Total & 89 \\
\hline
\end{tabular}

reaction between B. burgdorferi and human B-cells. In order to understand the gene diversity of the $41 \mathrm{kD}$ flagellin of Chinese strains, especially on the human B-cell epitopes, we sequenced and analyzed the $41 \mathrm{kD}$ flagellin gene of 89 strains of four genotypes in China.

\section{Materials and Methods}

2.1. Strain Selection. We selected 89 B. burgdorferi strains which were isolated in Beijing Municipality and 11 provinces and autonomous regions in China (Table 1). These strains were genotyped by multilocus sequence analysis (MLSA) in previous study [17]. 89 strains belonged to four genotypes, which were B.b.s.s, B. garinii, B. afzelii, and B. valaisiana. According to the genotypic ratio of $B$. burgdorferi strains in China, we selected 1 B.b.s.s strain, 67 B. garinii strains, 16 B. afzelii strains, and 5 B. valaisiana strains in this study (Table 2).

2.2. Culture and PCR. These strains were cultured in Barbour-Stoenner-Kelly (BSK) medium, collected by centrifuging at $13000 \mathrm{rpm} / \mathrm{min}$, and then heat-inactivated at $100^{\circ} \mathrm{C}$. DNA obtained by this method was used as a template for amplifying the gene of $41 \mathrm{kDa}$ flagellin. The nucleotide sequences of the primers used in this study were designed with Primer 5 software according to B31 genome sequence and were as follows: $5^{\prime}$-TTATCATGGAGGAATGATAT- $3^{\prime}$ and $5^{\prime}$-ACCCTACTCAAAGCAAACTC- $3^{\prime}$. PCR was performed in a total volume of $50 \mu \mathrm{L}$. The PCR mix contained $25 \mu \mathrm{L}$ PCR buffer, $20 \mathrm{pM}$ of each primer, $2.5 \mathrm{mM}$ each of four dNTPs, and 1 U DNA Taq Polymerase (Takara). Amplification was performed for $10 \mathrm{~min}$ of initial denaturation at $94^{\circ} \mathrm{C} ; 35$ cycles under the following conditions: $1 \mathrm{~min}$ of denaturation at $94^{\circ} \mathrm{C}, 1 \mathrm{~min}$ of annealing at $52^{\circ} \mathrm{C}$, and $1 \mathrm{~min}$ of extension at $72^{\circ} \mathrm{C} ; 10 \mathrm{~min}$ of final extension at $72^{\circ} \mathrm{C}$. Negative control (reagent only, no DNA) was included when the PCR was performed. The positive control was $300 \mathrm{ng}$ DNA from the B31 of B.b.s.s genotype, which was the standard strain in the United States. The presence and size of PCR products were
TABLE 2: Genotypes of 89 Chinese strains by MLSA.

\begin{tabular}{lc}
\hline MLSA genotypes & Number of strains \\
\hline Borrelia burgdorferi sensu stricto & 1 \\
Borrelia garinii & 67 \\
Borrelia afzelii & 16 \\
Borrelia valaisiana & 5 \\
Total & 89 \\
\hline
\end{tabular}

determined by electrophoresis on $1.5 \%$ agarose gel in Trisboric acid-EDTA buffer followed by staining with goldview. We performed all of the PCRs at least twice to validate the reproducibility.

2.3. Analytical Methods. The sequences of all PCR products were determined with an ABI 3730xl DNA Analysis. Distances were calculated using the neighbor-joining method. The sequences which contained 46-1011 bp of $41 \mathrm{kD}$ flagellin were compared by MEGA5.10 software [18].

\section{Results}

We amplified the gene encoding the $41 \mathrm{kDa}$ flagellin, obtained PCR products of all 89 strains, and then compared the sequences based on the $41 \mathrm{kDa}$ flagellin gene sequence of $\mathrm{B} 31$. As a result, the nucleotide and amino acids sequences of $41 \mathrm{kD}$ flagellin in B.b.s.s strain CS4 were exactly identical to B31, whereas there were 133 single nucleotide polymorphisms, consisting of 15 nonsynonymous mutations and 118 synonymous mutations in $41 \mathrm{kDa}$ flagellin genes of the remaining 88 strains (Table 3). As shown in Table 3, except AA position 105 and 279 mutations, 13 nonsynonymous mutations located in epitope region. AA positions 205 and 215 displayed higher polymorphism among 15 nonsynonymous mutations. Strains with other three genotypes, B. garinii, B. afzelii, and $B$. valaisiana, were almost all changed at AA positions 205 and 215. In addition, AA position 205 had two variants, T(Thr)$\mathrm{A}(\mathrm{Ala})$ and $\mathrm{T}(\mathrm{Thr})-\mathrm{S}(\mathrm{Ser})$. Moreover, the changes of AA positions 208, 213, and 279 were unique to $B$. garinii strains; AA positions $17,191,199,216$, and 230 were unique to $B$. afzelii strains and AA positions 142 and 260 were unique to $B$. valaisiana. The specific mutation sites for each genotype could be used for genotyping Chinese B. burgdorferi strains.

The $41 \mathrm{kD}$ flagellin harbored forty-four human B-cell epitopes [16]. Because two of forty-four human B-cell epitopes were not mapped to B31, we analyzed the changes of forty-two epitopes (Table 4). In our study, thirteen of 15 nonsynonymous mutations occurred in the epitope region of $41 \mathrm{kD}$ flagellin and thirty of 42 human B-cell epitopes were altered due to all 13 nonsynonymous mutations in the epitope region. The changed epitopes mainly concentrated in central region of $41 \mathrm{kD}$ flagellin, which was about AA positions 131266 [19].

From Table 3 and Figure 1, we can see that the amino acid sequence of strains within the genotype (16 B. afzelii and 5 B. valaisiana) showed almost $100 \%$ identity, respectively. Nevertheless, 67 B. garinii strains showed more sequence 
TABLE 3: Base changes (nonsynonymous mutations) in $41 \mathrm{kD}$ flagellin ${ }^{\&}$.

\begin{tabular}{|c|c|c|c|c|c|c|}
\hline \multirow{2}{*}{ Base change } & \multirow{2}{*}{ AA position } & \multicolumn{4}{|c|}{ Number of changed strains } & \multirow{2}{*}{ Distribution } \\
\hline & & B.b.s.s & B.g & B. $a$ & B.v & \\
\hline GGC(G)-GCC(A) & 17 & - & - & 16 & - & $\mathrm{ER}^{\#}$ \\
\hline GCA(A)-TCA(S) & 105 & - & - & 16 & 5 & $\mathrm{NER}^{\#}$ \\
\hline TCT(S)-GCT(A) & 142 & - & - & - & 5 & ER \\
\hline $\mathrm{AGA}(\mathrm{R})-\mathrm{AAA}(\mathrm{K})$ & 146 & - & - & 16 & 5 & ER \\
\hline GCA(A)-TCA(S) & 191 & - & - & 16 & - & ER \\
\hline TCT(S)-GCT(A) & 199 & - & - & 16 & - & ER \\
\hline ACT(T)-GCT(A) & 205 & - & 66 & 16 & - & ER \\
\hline ACT(T)-TCT(S) & 205 & - & - & - & 5 & ER \\
\hline GCT(A)-ACT(T) & 208 & - & 66 & - & - & ER \\
\hline GAG(E)-GAC(D) & 213 & - & 1 & - & - & ER \\
\hline GTT(V)-GCT(A) & 215 & - & 66 & 16 & 5 & ER \\
\hline CAG(Q)-GAG(E) & 216 & - & - & 16 & - & ER \\
\hline $\mathrm{GCA}(\mathrm{A})-\mathrm{ACA}(\mathrm{T})$ & 224 & - & 1 & 16 & - & ER \\
\hline TCT(S)-ACT(T) & 230 & - & - & 16 & - & ER \\
\hline $\operatorname{ATA}(\mathrm{I})-\mathrm{GTG}(\mathrm{V})$ & 260 & - & - & - & 5 & ER \\
\hline $\operatorname{AAT}(\mathrm{N})-\mathrm{GAT}(\mathrm{D})$ & 279 & - & 50 & - & - & NER \\
\hline
\end{tabular}

${ }^{2}$ The CDS of $41 \mathrm{kD}$ flagellin of Borrelia burgdorferi sensu stricto $\mathrm{B} 31$ has been used as the reference sequence.

${ }^{\#}$ ER: epitope region; ${ }^{\#}$ NER: nonepitope region.

variations and could be further divided into two major subgroups. Compared with the same genotype strains, three of $67 \mathrm{~B}$. garinii strains, JL13, JC1-13, and JC1-15, showed obvious diversity. The only one strain with mutation at AA position 213 was JC1-13. For the mutation site of AA position 224, JC1-15 was the only one of 67 B. garinii strains.

\section{Discussion}

In this study, we selected 89 B. burgdorferi strains in China that derived from very large geographical areas and had four MLSA genotyping patterns. Hence, the data provided by them was representative of the genetic diversity that might be presented in China, at least to some extent.

The $41 \mathrm{kD}$ flagellin protein is the predominant component of B. burgdorferi's flagellar filament core $[20,21]$. As reported by Namba et al. [22], X-ray fiber diffraction analysis of the secondary flagellin structure indicated that the terminal portions of the protein influence the structure of the filament and are located toward the center of the filament, whereas the central region of the protein is not involved in conformation and is located on the outside of the filament structure. Some studies have demonstrated that this protein and its central region could elicit the immune response to $B$. burgdorferi $[15,23,24]$. In addition, the central region of $41 \mathrm{kD}$ flagellin was specific to $B$. burgdorferi and had no cross-reactive with other Borrelia species, such as Borrelia recurrentis [24]. However, it has been reported that flagellin genes cloned from several $B$. burgdorferi strains had been shown to be highly conserved [15]. In our study, fifteen nonsynonymous mutations were discovered among 89 strains including four B. burgdorferi genotypes; thirteen of 15 nonsynonymous mutations were found in the epitope region, and some of them were unique to each genotype. It is suggested that the sensitivity including $41 \mathrm{kD}$ flagellin of four genotypes may be improved in serodiagnosis assay.

Studies in human pathogenic viruses, bacteria, and protozoa have revealed that the genes encoding antigens tend to be highly variable as a consequence of diversifying selection to evade host immunity [25-28]. A few studies have demonstrated that VlsE and OspC were critical for immune evasion of B. burgdorferi $[1,29-32]$. The $41 \mathrm{kD}$ flagellin protein containing forty-four human B-cell epitopes may play an important role in humoral immunity between $B$. burgdorferi and human B-cells. We found that the epitope regions of this protein were diverse; $71.43 \%(30 / 42)$ of the B-cell epitopes presented AA changes, which may reflect ongoing immune evasion. The distribution of these nonsynonymous mutations was located mainly in amino acid positions 142279 , consistent with the central region of $41 \mathrm{kD}$ flagellin antigen.

The protein function may be affected by the changed AA's polarity. The changes of AA positions 17, 142, 199, and 205 (TA) caused the decreasing of hydrophilicity. On the contrary, AA positions 105, 191, 208, and 224 led to the increase of hydrophilicity. The changes of AA's polarity may have a slight impact on the capacity of flagellin penetration, resulting in differences in protein function of each genotype strain.

Based on the diversity of amino acid in $41 \mathrm{kD}$ flagellin, 89 B. burgdorferi strains were clustered into four groups (Figure 1). These four groups by clustering were consistent with MLSA genotyping pattern. As shown in Figure 1, the amino acid sequences of strains were conserved within each genotype of B.b.s.s, B. afzelii, and B. valaisiana, whereas the strains of $B$. garinii and all strains among four genotypes showed obvious diversity. In particular, the strain of JC1-15 belonging to $B$. garinii was clustered in Borrelia burgdorferi sensu stricto. However, further investigations will be needed 
TABLE 4: Amino acid changes of the B-cell epitopes included in $41 \mathrm{kD}$ flagellin antigen.

\begin{tabular}{|c|c|c|}
\hline IEDB-ID & Epitopes & Base change \\
\hline 26607 & IINHNTSAINASRNNGINAANLSKTQEKLSSGYRIN & GGC(G)-GCC(A) \\
\hline 27732 & INRIADQAQY & No change \\
\hline 27733 & INRIADQAQYNQMHMLSNKSASQNVRTAEELGMQPAKI & TCT(S)-GCT(A), AGA(R)-AAA(K) \\
\hline 54118 & RIADQAQYNQ & No change \\
\hline 752 & ADQAQYNQMH & No change \\
\hline 50350 & QAQYNQMHML & No change \\
\hline 53012 & QYNQMHMLSN & No change \\
\hline 45589 & NQMHMLSNKS & No change \\
\hline 41667 & MHMLSNKSAS & $\mathrm{TCT}(\mathrm{S})-\mathrm{GCT}(\mathrm{A})$ \\
\hline 42062 & MLSNKSASQN & TCT(S)-GCT(A) \\
\hline 59856 & SNKSASQNVR & TCT(S)-GCT(A), AGA(R)-AAA(K) \\
\hline 7895 & DEAIAVNIYAANVANLFSGEGAQTAQAAPVQEGVQQE & $\begin{array}{c}\text { GCA(A)-TCA(S), TCT(S)-GCT(A), } \\
\text { ACT(T)-G(T)CT(AS), GCT(A)-ACT(T) } \\
\text { GAG(E)-GAC(D), GTT(V)-GCT(A) } \\
\text { CAG(Q)-GAG(E) }\end{array}$ \\
\hline 35977 & LFSGEGAQTAQAAPVQEGVQQEGAQQPAPATAPSQGGVNSPVNVT & $\begin{array}{l}\text { TCT(S)-GCT(A), ACT(T)-G(T)CT(A } \\
\text { S)GCT(A)-ACT(T), GAG(E)-GAC(D), } \\
\text { GTT(V)-GCT(A), CAG(Q)-GAG(E), } \\
\text { GCA(A)-ACA(T), TCT(S)-ACT(T) }\end{array}$ \\
\hline 3341 & ANLFSGEGAQTAQ & TCT(S)-GCT(A), ACT(T)-G(T)CT(A S) \\
\hline 58007 & SGEGAQTAQAAPV & $\begin{array}{c}\mathrm{TCT}(\mathrm{S})-\mathrm{GCT}(\mathrm{A}), \mathrm{ACT}(\mathrm{T})-\mathrm{G}(\mathrm{T}) \mathrm{CT}(\mathrm{A} \mathrm{S}) \\
\mathrm{GCT}(\mathrm{A})-\mathrm{ACT}(\mathrm{T})\end{array}$ \\
\hline 52474 & QTAQAAPVQEGVQ & $\begin{array}{c}\text { ACT(T)-G(T)CT(A S), GCT(A)-ACT(T) } \\
\text { GAG(E)-GAC(D), GTT(V)-GCT(A) }\end{array}$ \\
\hline 62967 & TAQAAPVQEG & $\begin{array}{c}\mathrm{ACT}(\mathrm{T})-\mathrm{G}(\mathrm{T}) \mathrm{CT}(\mathrm{A} \mathrm{S}), \mathrm{GCT}(\mathrm{A})-\mathrm{ACT}(\mathrm{T}) \\
\text { GAG(E)-GAC(D) }\end{array}$ \\
\hline 62968 & TAQAAPVQEGVQQEGAQQPAPA & $\begin{array}{c}\text { ACT(T)-G(T)CT(A S), GCT(A)-ACT(T) } \\
\text { GAG(E)-GAC(D), GTT(V)-GCT(A) } \\
\text { CAG(Q)-GAG(E), GCA(A)-ACA(T) }\end{array}$ \\
\hline 50213 & QAAPVQEGVQ & $\begin{array}{c}\text { GCT(A)-ACT(T), GAG(E)-GAC(D) } \\
\text { GTT(V)-GCT(A) }\end{array}$ \\
\hline 379 & AAPVQEGVQQEGA & $\begin{array}{l}\text { GCT(A)-ACT(T), GAG(E)-GAC(D) } \\
\text { GTT(V)-GCT(A), CAG(Q)-GAG(E) }\end{array}$ \\
\hline 3893 & APVQEGVQQE & $\begin{array}{c}\text { GAG(E)-GAC(D), GTT(V)-GCT(A) } \\
\text { CAG(Q)-GAG(E) }\end{array}$ \\
\hline 70549 & VQEGVQQEGA & $\begin{array}{c}\text { GAG(E)-GAC(D), GTT(V)-GCT(A) } \\
\text { CAG(Q)-GAG(E) }\end{array}$ \\
\hline 70550 & VQEGVQQEGAQQP & $\begin{array}{c}\text { GAG(E)-GAC(D), GTT(V)-GCT(A) } \\
\text { CAG(Q)-GAG(E) }\end{array}$ \\
\hline 50610 & QEGVQQEGAQQPAP & $\begin{array}{l}\text { GAG(E)-GAC(D), GTT(V)-GCT(A) } \\
\text { CAG(Q)-GAG(E), GCA(A)-ACA(T) }\end{array}$ \\
\hline 12306 & EGVQQEGAQQ & $\begin{array}{c}\text { GAG(E)-GAC(D), GTT(V)-GCT(A), } \\
\text { CAG(Q)-GAG(E) }\end{array}$ \\
\hline 12307 & EGVQQEGAQQPA & $\begin{array}{l}\text { GAG(E)-GAC(D), GTT(V)-GCT(A) } \\
\text { CAG(Q)-GAG(E), GCA(A)-ACA(T) }\end{array}$ \\
\hline 70628 & VQQEGAQQPA & $\begin{array}{c}\text { GTT(V)-GCT(A), CAG(Q)-GAG(E), } \\
\text { GCA(A)-ACA(T) }\end{array}$ \\
\hline 52010 & QQEGAQQPAPATA & CAG(Q)-GAG(E), GCA(A)-ACA(T) \\
\hline 50597 & QEGAQQPAPA & CAG(Q)-GAG(E), GCA(A)-ACA(T) \\
\hline 51693 & QPAPATAPSQGGV & GCA(A)-ACA(T), TCT(S)-ACT(T) \\
\hline 3820 & APSQGGVNSPVNV & TCT(S)-ACT(T) \\
\hline 3821 & APSQGGVNSPVNVTTTVDANTSLAKIENAIRMISDQRANLGAFQNR & TCT(S)-ACT(T), ATA(I)-GTG(V) \\
\hline
\end{tabular}


TABle 4: Continued.

\begin{tabular}{lcc}
\hline IEDB-ID & Epitopes & Base change \\
\hline 25890 & IENAIRMISD & ATA(I)-GTG(V) \\
43169 & NAIRMISDQR & ATA(I)-GTG(V) \\
28340 & IRMISDQRAN & ATA(I)-GTG(V) \\
41672 & MISDQRANLG & ATA(I)-GTG(V) \\
57265 & SDQRANLGAF & No change \\
52186 & QRANLGAFQN & No change \\
3342 & ANLGAFQNRL & No change \\
36055 & LGAFQNRLES & No change \\
1379 & AFQNRLESIK & No change \\
65265 & TMTDEVVAATTNSILTQSAMAMIAQANQVPQYVLSLLR & No change
\end{tabular}

Note: letters in bold font in the table represent the mutated amino acids in epitopes.

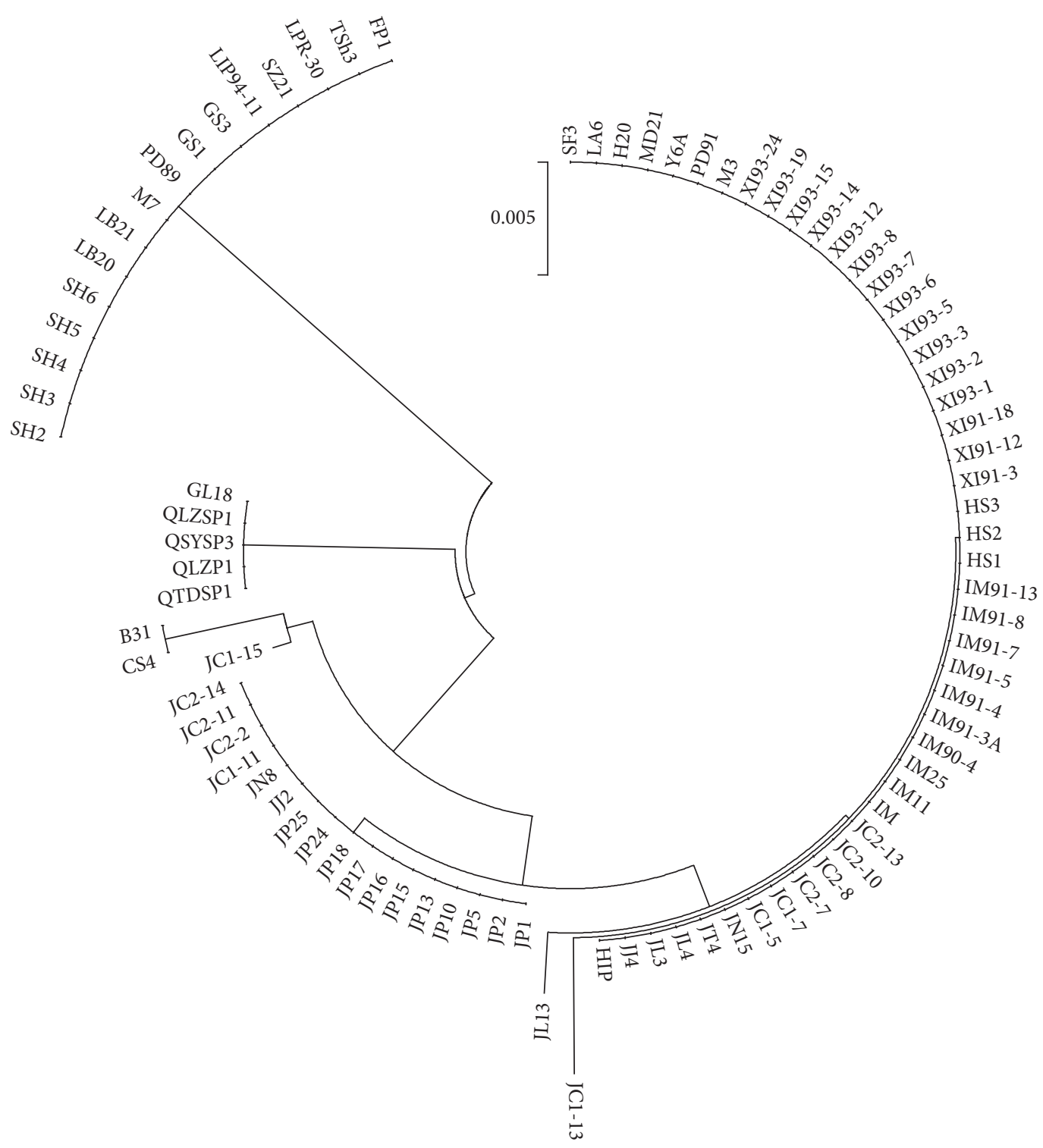

Figure 1: Phylogenetic analysis of 89 strains based on amino acid sequence of $41 \mathrm{kD}$ flagellin. 
to determine whether the observed changes are due to immune pressure, other selection pressure, or mere random genetic mutation.

\section{Conclusion}

In China, nonsynonymous mutations and changed human Bcell epitopes exist in $41 \mathrm{kD}$ flagellin of B. burgdorferi sensu lato strains that might affect the function of the antigen and reflect ongoing immune evasion. On the other hand, these changes should be considered in serodiagnosis of Lyme disease.

\section{Competing Interests}

The authors declare that they have no competing interests.

\section{Acknowledgments}

The authors thank the staffs of the respective institutes in Beijing Municipality and 11 provinces and autonomous regions in China for their excellent contribution to this study. This work was funded by grants from the National Science and Technology Major Project for Infectious Diseases (2016ZX10004001-004 and 2012ZX10004-215).

\section{References}

[1] D. Brisson, D. Drecktrah, C. H. Eggers, and D. S. Samuels, "Genetics of Borrelia burgdorferi," Annual Review of Genetics, vol. 46, pp. 515-536, 2012.

[2] A. C. Steere, J. Coburn, and L. Glickstein, "The emergence of Lyme disease," Journal of Clinical Investigation, vol. 113, no. 8, pp. 1093-1101, 2004.

[3] Z. Hubálek, "Epidemiology of lyme borreliosis," Current Problems in Dermatology, vol. 37, pp. 31-50, 2009.

[4] R. A. Sykes and P. Makiello, "An estimate of Lyme borreliosis incidence in Western Europe," Journal of Public Health, 2016.

[5] B. M. Kuehn, "CDC estimates 300000 US cases of lyme disease annually," Journal of the American Medical Association, vol. 310, no. 11, p. 1110, 2013.

[6] A. F. Hinckley, N. P. Connally, J. I. Meek et al., "Lyme disease testing by large commercial laboratories in the United States," Clinical Infectious Diseases, vol. 59, no. 5, pp. 676-681, 2014.

[7] B. Wilske, "Epidemiology and diagnosis of Lyme borreliosis," Annals of Medicine, vol. 37, no. 8, pp. 568-579, 2005.

[8] X.-B. Ni, N. Jia, B.-G. Jiang et al., "Lyme borreliosis caused by diverse genospecies of Borrelia burgdorferi sensu lato in northeastern China," Clinical Microbiology and Infection, vol. 20, no. 8, pp. 808-814, 2014.

[9] D. Richter, D. B. Schlee, R. Allgöwer, and F.-R. Matuschka, "Relationships of a novel Lyme disease spirochete, Borrelia spielmani sp. nov., with its hosts in Central Europe," Applied and Environmental Microbiology, vol. 70, no. 11, pp. 6414-6419, 2004.

[10] G. Margos, S. A. Vollmer, N. H. Ogden, and D. Fish, "Population genetics, taxonomy, phylogeny and evolution of Borrelia burgdorferi sensu lato," Infection, Genetics and Evolution, vol. 11, no. 7, pp. 1545-1563, 2011.

[11] S. Etti, R. Hails, S. M. Schäfer et al., "Habitat-specific diversity of Borrelia burgdorferi sensu lato in Europe, exemplified by data from Latvia," Applied and Environmental Microbiology, vol. 69, no. 5, pp. 3008-3010, 2003.

[12] E. Ozdenerol, "GIS and remote sensing use in the exploration of lyme disease epidemiology," International Journal of Environmental Research and Public Health, vol. 12, no. 12, pp. 1518215203, 2015.

[13] G. Stanek, G. P. Wormser, J. Gray, and F. Strle, "Lyme borreliosis," The Lancet, vol. 379, no. 9814, pp. 461-473, 2012.

[14] S. Z. Sultan, A. Manne, P. E. Stewart et al., "Motility is crucial for the infectious life cycle of borrelia burgdorferi," Infection and Immunity, vol. 81, no. 6, pp. 2012-2021, 2013.

[15] W. Jiang, B. J. Luft, W. Schubach, R. J. Dattwyler, and P. D. Gorevic, "Mapping the major antigenic domains of the native flagellar antigen of Borrelia burgdorferi," Journal of Clinical Microbiology, vol. 30, no. 6, pp. 1535-1540, 1992.

[16] R. Vita, L. Zarebski, J. A. Greenbaum et al., "The immune epitope database 2.0," Nucleic Acids Research, vol. 38, supplement 1, pp. D854-D862, 2009.

[17] Q. Hao, X. Hou, Z. Geng, and K. Wan, "Distribution of Borrelia burgdorferi sensu lato in China," Journal of Clinical Microbiology, vol. 49, no. 2, pp. 647-650, 2011.

[18] K. Tamura, D. Peterson, N. Peterson, G. Stecher, M. Nei, and S. Kumar, "MEGA5: molecular evolutionary genetics analysis using maximum likelihood, evolutionary distance, and maximum parsimony methods," Molecular Biology and Evolution, vol. 28, no. 10, pp. 2731-2739, 2011.

[19] C. Rasiah, E. Schiltz, J. Reichert, and A. Vogt, "Purification and characterization of a tryptic peptide of Borrelia burgdorferi flagellin, which reduces cross-reactivity in immunoblots and ELISA," Journal of General Microbiology, vol. 138, no. 1, pp. 147154, 1992.

[20] R. J. Limberger, "The periplasmic flagellum of spirochetes," Journal of Molecular Microbiology and Biotechnology, vol. 7, no. 1-2, pp. 30-40, 2004.

[21] C. W. Wolgemuth, N. W. Charon, S. F. Goldstein, and R. E. Goldstein, "The flagellar cytoskeleton of the spirochetes," Journal of Molecular Microbiology and Biotechnology, vol. 11, no. 3-5, pp. 221-227, 2006.

[22] K. Namba, I. Yamashita, and F. Vonderviszt, "Structure of the core and central channel of bacterial flagella," Nature, vol. 342, no. 6250, pp. 648-654, 1989.

[23] R. Wallich, S. E. Moter, M. M. Simon, K. Ebnet, A. Heiberger, and M. D. Kramer, "The Borrelia burgdorferi flagellumassociated 41-kilodalton antigen (flagellin): molecular cloning, expression, and amplification of the gene," Infection and Immunity, vol. 58, no. 6, pp. 1711-1719, 1990.

[24] J. M. Robinson, T. J. Pilot-Matias, S. D. Pratt, C. B. Patel, T. S. Bevirt, and J. C. Hunt, "Analysis of the humoral response to the flagellin protein of Borrelia burgdorferi: cloning of regions capable of differentiating Lyme disease from syphilis," Journal of Clinical Microbiology, vol. 31, no. 3, pp. 629-635, 1993.

[25] P. Farci, A. Shimoda, A. Coiana et al., "The outcome of acute hepatitis C predicted by the evolution of the viral quasispecies," Science, vol. 288, no. 5464, pp. 339-344, 2000.

[26] D. C. Jeffares, A. Pain, A. Berry et al., "Genome variation and evolution of the malaria parasite Plasmodium falciparum," Nature Genetics, vol. 39, no. 1, pp. 120-125, 2007.

[27] R. Urwin, J. E. Russell, E. A. L. Thompson, E. C. Holmes, I. M. Feavers, and M. C. J. Maiden, "Distribution of surface protein variants among hyperinvasive meningococci: implications for vaccine design," Infection and Immunity, vol. 72, no. 10, pp. 5955-5962, 2004. 
[28] Y. Jiang, X. Dou, W. Zhang et al., "Genetic diversity of antigens Rv2945c and Rv0309 in Mycobacterium tuberculosis strains may reflect ongoing immune evasion," FEMS Microbiology Letters, vol. 347, no. 1, pp. 77-82, 2013.

[29] S. J. Norris, "vls Antigenic variation systems of lyme disease borrelia: eluding host immunity through both random, segmental gene conversion and framework heterogeneity," Microbiology Spectrum, vol. 2, no. 6, 2014.

[30] A. S. Rogovskyy and T. Bankhead, "Variable VlsE is critical for host reinfection by the Lyme disease spirochete," PLoS ONE, vol. 8, no. 4, Article ID e61226, 2013.

[31] S. V. Seemanapalli, Q. Xu, K. McShan, and F. T. Liang, "Outer surface protein $\mathrm{c}$ is a dissemination-facilitating factor of borrelia burgdorferi during mammalian infection," PLOS ONE, vol. 5, no. 12, Article ID e15830, 2010.

[32] Q. Xu, K. McShan, and F. T. Liang, "Identification of an ospC operator critical for immune evasion of Borrelia burgdorferi," Molecular Microbiology, vol. 64, no. 1, pp. 220-231, 2007. 

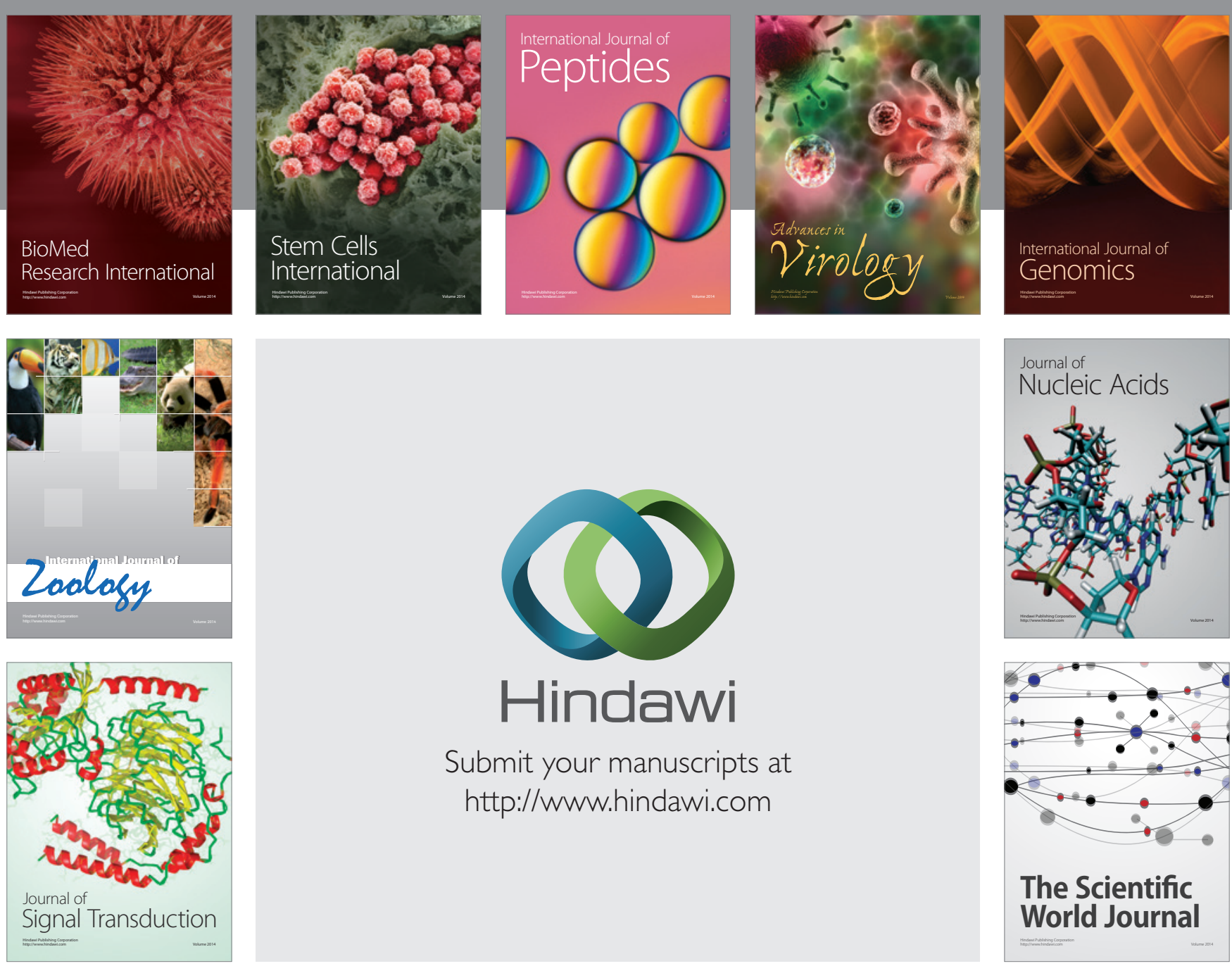

Submit your manuscripts at

http://www.hindawi.com
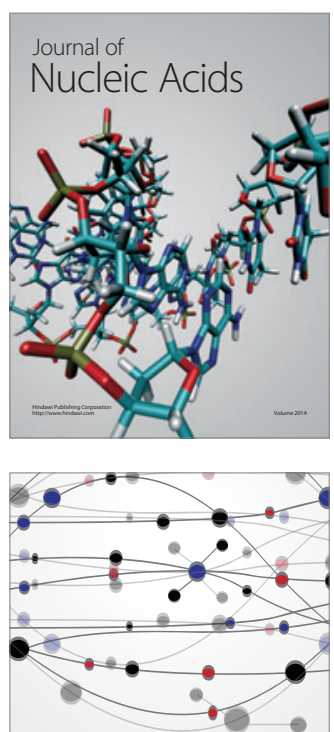

The Scientific World Journal
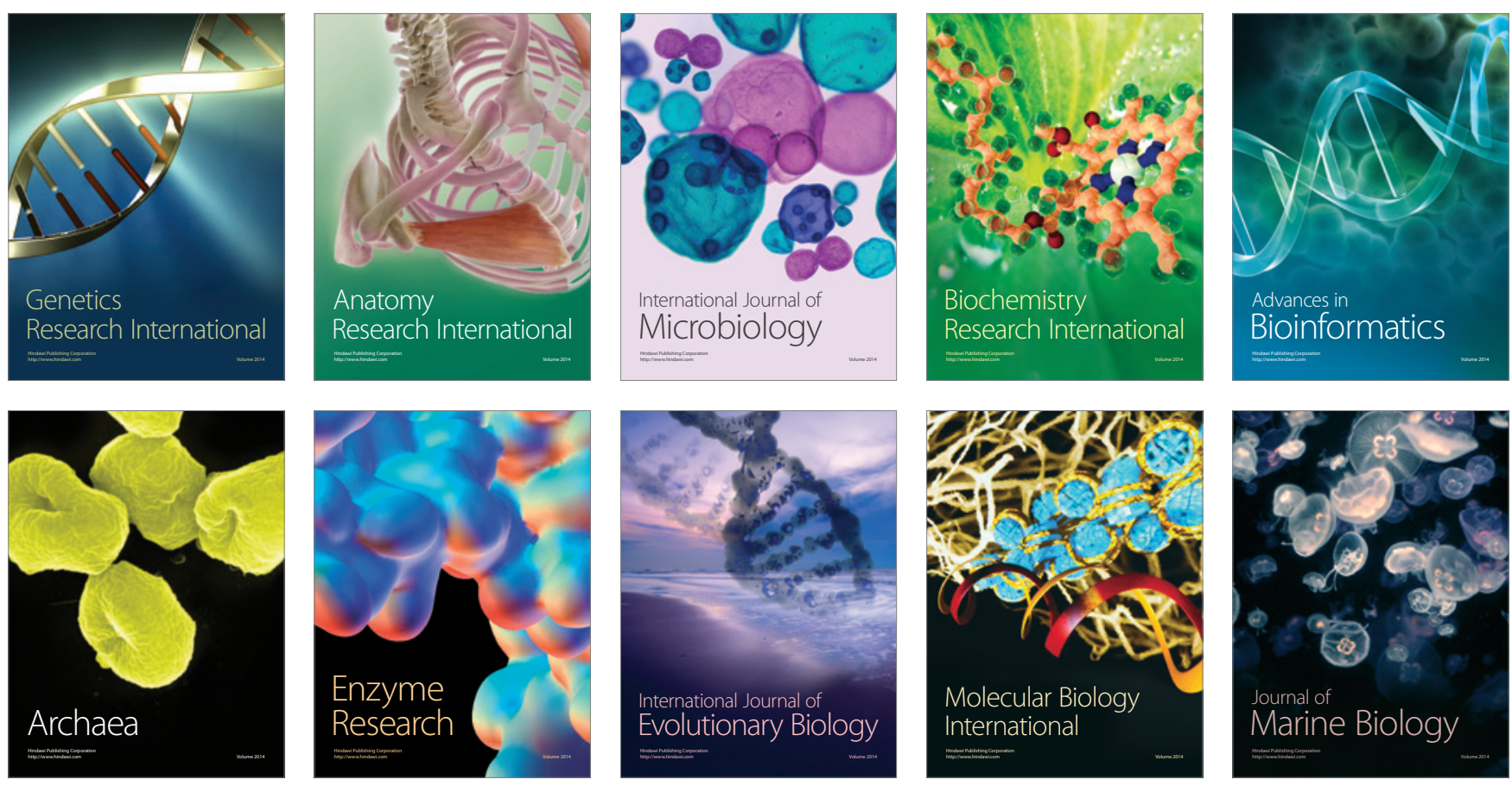